\title{
Design Thinking to Create a Remote Patient Monitoring Platform for Older Adults' Homes
}

\author{
H. A. Kolnick, Jennifer E. Miller, Olivia Dupree, Lisa Gualtieri, PhD, ScM \\ Department of Public Health and Community Medicine, Tufts University School of Medicine
}

\begin{abstract}
How might clinicians collect the vitals needed for effective scheduled video visits for older adults? This challenge was presented by AARP to graduate students in a Digital Health course at Tufts University School of Medicine. The design thinking process was used to create a product that would meet this need, keeping the needs and constraints of older adults, especially those with chronic conditions or other barriers to health, central to the solution. The initial steps involved understanding and empathizing with the target audience through interviews and by developing personas and scenarios that identified barriers and opportunities. The later steps were to ideate potential solutions, design a prototype, and define product success. The design thinking process led to the design of Home Health Hub, a remote patient monitoring (RPM) platform designed to meet the unique needs of older adults. Additionally, Home Health Hub can conceivably benefit all users of telehealth, regardless of health status-an important need during the COVID-19 pandemic, and in general due to increased use of virtual visits. Home Health Hub is one example of what can be achieved with the dedicated use of design thinking. The design thinking process can benefit public health practice as a whole by encouraging practitioners to delve into a problem to find the root causes and empathize with the needs and constraints of stakeholders to design innovative, human-centered solutions.

*Correspondence: lisa.gualtieri@tufts.edu

DOI: 10.5210/ojphi.v13i1.11582

Copyright (C2021 the author(s)

This is an Open Access article. Authors own copyright of their articles appearing in the Online Journal of Public Health Informatics. Readers may copy articles without permission of the copyright owner(s), as long as the author and OJPHI are acknowledged in the copy and the copy is used for educational, not-for-profit purposes.
\end{abstract}

\section{Background}

A growing population of older adults (people 50 years of age and older) in the US and increased adoption of telehealth have given rise to a need for accessible and effective methods to gather patient vitals remotely. Telehealth visits are increasing, and there is a market for and widespread interest in remote patient monitoring (RPM) devices. There are already RPM devices and systems on the market which meet the needs of select populations. The authors sought to design an RPM platform that would combine the best features of existing RPM solutions and designate a space in the home for health care to meet the needs of older adults regardless of level of mobility, digital literacy, access to transportation, and wireless internet [1]. 


\subsection{Telehealth Adoption}

Telehealth is the use of electronic information and telecommunications technologies to provide clinical health care, health education, public health and health administration over a long-distance [2]. Many different technologies can be used to provide health care when a patient and provider aren't in the same location at the same time including videoconferencing, imaging, streaming media, the internet, and wireless communication. Telemedicine, on the other hand, refers specifically to remote clinical health care, while telehealth refers to a broader range of healthrelated services.

In 2017, the American Hospital Association (AHA) found that 76 percent of U.S. hospitals connect with patients and consulting practitioners using telehealth [3]. In March of 2020 early in the pandemic, telehealth visits increased by 154 percent compared to 2019. Providers were forced to perfect a complicated system of health information technology virtually overnight. While use of telehealth has been steadily increasing for decades, it has recently been the focus of health providers and public health departments nationwide as COVID-19 has forced people into their homes and away from hospitals to avoid infection [1]. To reduce the spread of the coronavirus, telehealth options for needed care have proliferated. It is now possible to use telehealth for an annual wellness visit, prescription consultation, dermatology, eye exams, nutrition counseling, mental health counseling, and even urgent care conditions like sinusitis, urinary tract infections, rash, or pain [4].

In addition to reduction of exposure to COVID-19, there are many other benefits to the use of telehealth. Telehealth can reduce the need to commute and make care more accessible for people by reducing transportation-related barriers for those with low mobility, those who live in rural areas, those who don't drive and those who don't have access to a vehicle or public transportation. People without access to child care, those who can't get the time off of work, or those who live in an area with extreme heat or weather conditions can also benefit. Telehealth is also often offered with little to no co-pay and allows for overall reduced spending among all stakeholders, patient, provider, and insurer alike. Telehealth is particularly beneficial for older adults, the focus of this design thinking project, because it allows them to meet with their providers and own their care, regardless of level of mobility, often without help from a loved one. In more ways than one, telehealth helps to close the equity gap caused by many of the social determinants of health.

\subsection{Remote Patient Monitoring}

One major concern shared by patients and providers alike regards the collection of patient vitals. The need for providers to know their patients' vital signs is particularly crucial among older adults and those with chronic conditions such as hypertension and diabetes. Many solutions to this need exist in various capacities. Remote vital sign collection for telehealth visits, or remote patient monitoring, can be done in a variety of ways including kiosks and home kits.

Kiosks refer to stations in pharmacies, grocery stores, or other public locations where patients can have their vitals checked in a self-service fashion. Kits, or "home kits" refers to a suite of RPM devices that can be kept and used at home: a scale, thermometer, blood pressure cuff/monitor, blood glucose monitor, pulse oximetry, and even a smartwatch - many of which now possess electrocardiogram (ECG) capabilities, fall detection, and respiratory rate tracking. Use of and 
interest in RPM devices is at an all-time high. According to a 2019 survey conducted by a healthcare solutions provider, 64 percent of participants over the age of 40 said they would use a health monitoring device if it would reduce their number of physical trips to the doctor or hospital $[5]$.

An analysis of the strengths, weaknesses, opportunities, and threats (SWOT) of kiosks and home kits was used to determine where to focus the ideation stage of the design thinking process and refine the space of possible solutions (complete SWOT analyses available in Appendix A). In this analysis, we found that kiosks had the advantages of being cost-effective and not raising issues of storage or maintenance for patients. Yet they were not accessible for patients living in rural areas or those with limited mobility. Further, cleanliness and disinfection were issues, especially during a pandemic. Existing home kits, while convenient and hygienic, were still found to possess several weaknesses related to digital literacy, Wi-Fi access, and the potential for error with non-medicalgrade products.

\subsection{Remote Patient Monitoring Platforms}

We shifted our research from kiosks and home kits to RPM platforms providing devices for inhome use available on the market. The convenience and benefits of RPM could not be denied. Studies have shown that home RPM can increase medication compliance, improve patient satisfaction, and decrease emergency room (ER) visits, hospital admissions, and medical spending by all stakeholders [6].

RPM adoption by providers is high; 88 percent of healthcare providers have already invested in or are shopping RPM technologies, specifically to support chronically ill patients with increased risk for hospitalization [7]. We considered two popular platforms: Livongo and 100Plus. Livongo, a prototype of sorts, goes above and beyond what many other platforms are willing or able to do. 100Plus is simpler and similar to the majority of other platforms that exist for Medicare patients only.

Livongo intends to empower its members with chronic conditions to live fuller and healthier lives. They have specialists available to help support the patient to navigate their treatment plan, out-ofrange readings, and any other concerns that may arise. They claim to reduce deaths from diabetes by 21 percent, reduce heart attacks by 14 percent, and reduce peripheral heart disease by 43 percent. Livongo focuses on care for adults with specific health conditions and a high level of digital literacy [8].

100Plus offers a simple payment model and straightforward configuration of their devices. All of their devices are fully cellular and ready to use right out of the box-no Wi-Fi, Bluetooth, or SIM cards are needed. We believe this will be a key feature to support patients without internet or Wi$\mathrm{Fi}$ access. They work exclusively with providers to meet the needs of older adults with Medicare. Providers bill the Center for Medicare and Medicaid Services (CMS) for all CPT codes related to RPM and/or chronic care management. 100Plus profits from a percentage of the provider's reimbursement from one CPT code and a small fee charged to the patient. Providers are often able to increase revenue with this model due to CMS' 2020 increase of available reimbursement potential. 100Plus works specifically with Medicare patients and their products do not provide individualized feedback nor do they offer patients a portal to review and store results [9]. 


\section{Target audience}

A majority of older adults are open to using RPM devices when the practice translates to less time spent traveling to meet with their health care providers [5]. The high level of interest, combined with the increased benefit to the age group, led the authors to identify older adults as the primary user population in the design thinking project. In consideration of family members and health care professionals who assist with and provide care to older adults, we also identified a secondary user population: family and professional caregivers.

We identified which specific target populations of our overall user population would benefit most from an accessible and effective solution to collecting vitals remotely. The target populations identified were as follows: immunocompromised individuals and those with chronic conditions, those with concerns about visiting the doctor during the global COVID-19 pandemic, those living in rural locations, individuals with mobility issues or transportation barriers, and finally, any older adult with a preference for telehealth.

The process of defining and segmenting our audience also led the authors to identify individuals and groups who were perceived to be stakeholders in a potential solution. We determined that the main stakeholders would be patients aged 50 and older, health care providers, and insurance providers - namely, CMS. CMS is the largest payer of healthcare services in the country, and millions of older adults in our primary user population rely on Medicare to help cover the cost of their medical bills [10]. Other stakeholders we identified include producers and manufacturers of RPM devices.

Patients, and caregivers of patients, in long-term or skilled-care facilities would be least likely to benefit from our design-thinking solution. This is primarily due to the assumption that, in most cases, these facilities would already be in possession of devices to collect patient vitals and have health care providers on staff to conduct visits with patients.

\subsection{Interviews}

Designing and conducting interviews was an opportunity to learn more about stakeholder populations who are affected by the need for accessible and effective methods to gather vitals for telehealth visits. (The complete list of interview questions available in Appendix B). Four interviews were completed using a convenience sample, with a focus on collecting data related to internet access, smartphone ownership, comfort and perceived skill using digital technology, history of chronic conditions, and self-collecting vitals. Seventy-five percent of interviewees stated they had Wi-Fi, a smart phone, were comfortable using digital technology, and had a chronic condition. For patients who had taken vitals at home before, we asked several questions to understand perception and experience, including the level of perceived difficulty associated with taking their own vitals from home. Certain themes arose in the interviews that influenced the design process. One interviewee in her 70s mentioned the struggle to find her international normalized ratio (INR) kit whenever she needed to test the thickness of her blood. Another interviewee stated, "My whole bedroom is like a pharmacy now... I've got an entire cabinet of supplies here," in talking about storing supplies as a caregiver [11]. These responses highlighted our research and reinforced the need for a centralized place in the home dedicated to health. Additionally, we assessed whether interviewees believed taking vitals regularly to be important 
and to score level of difficulty. Finally, the interviews uncovered whether self-taken vitals were shared with doctors and if the measurements had any influence on the conversation that took place with their care provider.

\subsection{Personas and Scenarios}

The process of designing and conducting interviews led to the development of four unique personas who could potentially benefit from RPM solutions to support their telehealth use. (A complete list of personas and scenarios is in Appendix C).

Jim is a 78-year-old cisgender male veteran who lives in rural Minnesota. He lives with multiple chronic conditions, including cardiovascular disease, PTSD, and declining mobility. His social supports include a small circle of friends and his children-however, Jim values and wishes to protect his independence more as he ages. Jim learned from an advertisement in the mail that his health care facility is beginning to offer telehealth visits. The telehealth option would save him a considerable amount of time, as he is accustomed to frequent travel into the city to meet with his care team.

Billy is a 63-year-old African American cisgender male who has had high blood pressure for 10 years. He has been managing his high blood pressure with in-person visits to the doctors yearly. He has internet access at home and a smartphone but low digital literacy. Billy was recently diagnosed with Type 2 diabetes and would love to learn how to safely manage his care from home. This new diabetes diagnosis will require him to visit his doctor every three months. In early March, Billy visited his doctor to have his vitals checked and A1c tested. Shortly after this visit, COVID19 infections increased, and he was advised to stay home as much as possible. In June, he was due for more testing but was very uneasy going into the doctor's office due to the pandemic and his new diagnosis. Billy would love to learn how to safely manage his care from home, especially during a global pandemic.

Carmen is a 56-year-old cisgender female who is recently retired and loving her new free time. She had a mild heart attack in her late forties and has since taken charge of her health in a big way. She still has bouts of hypertension and works with her doctor to keep it at bay. She has Wi-Fi access at home and moderate digital literacy. She has an annual appointment coming up but doesn't want to travel all the way to see her doctor because it will mean missing the beginning of her beloved salsa class. She wants to be able to check her blood pressure and meet with her provider from home.

Caveh is a 33-year-old nonbinary/genderqueer physical therapist with Wi-Fi access and high digital literacy skills. They help take care of their father Rashad who has diabetes. Caveh prefers to accompany Rashad to his appointments but often has to miss one due to work restraints. They recently learned about the availability of telehealth visits from Rashad's primary care provider, but Caveh is worried that vital health information will be missed without access to the same tools used in the doctor's office. 


\section{Ideation}

The ideation process began by revisiting all of the existing solutions discovered while doing initial research. A SWOT analysis showed that kiosks are not ideal for rural patients nor those with limited mobility. Wearable solutions will not allow all needed health metrics to be collected like weight and blood pressure. The notion of an all-in-one wearable device was appealing but the technology does not yet exist. The evaluated platforms offered considerable products and features, but none that fully supported the four personas.

After evaluating existing solutions, the authors considered how the global pandemic is forcing people to spend more time at home - and how important it is to have dedicated areas in the home for specific activities, such as a home office. A source of inspiration was products which are designed to consolidate their function and save space in the home, such as Murphy Beds and folding desks. Initially, a pull-down/murphy bed-style compartment was considered an option for consolidating RPM and other health-related devices. It could be stored vertically and hinged to the wall for easy access when needed. This idea infiltrated the ideation process.

The ideation process also focused on the RPM tools the personas would need and how to organize them. Beyond the concept of consolidation and having a dedicated space in the home for all RPM devices, the product needed to be usable, cellular-enabled, and have a modular design.

\section{Introducing: Home Health Hub}

Home Health Hub is the culmination of research, interviews, persona and scenario development, and ideation. RPM-focused companies such as Livongo and 100Plus have already demonstrated success bringing RPM tools to patients in need of vital collection. Home Health Hub, goes a step further by offering a place in the home where all RPM devices can be stored and conveniently accessed. Home Health Hub is designed to reduce the likelihood for devices to get lost by consolidating multiple devices into one solution. It also opens opportunities to solve other problems, such as where patients can safely store medications. Home Health Hub creates one space in the home dedicated to health - offering a suite of RPM devices consolidated and housed in a modular, space-saving location which can also serve as a desk for patients to complete their telehealth visits.

\subsection{Prototype}

Our design thinking process led to the development of a low-fidelity prototype for Home Health Hub. When not in use, Home Health Hub folds into a size slightly larger than a standard briefcase (see Figure 1). The system features retractable handles which allow the user to easily carry it from storage to a surface for use. Alternatively, Home Health Hub can be securely attached to a wall using the included mounting hardware. The latter option allows Home Health Hub to act as a designated space in the home for health-monitoring activities. Home Health Hub plugs into a standard electrical outlet to supply power to the included devices. 


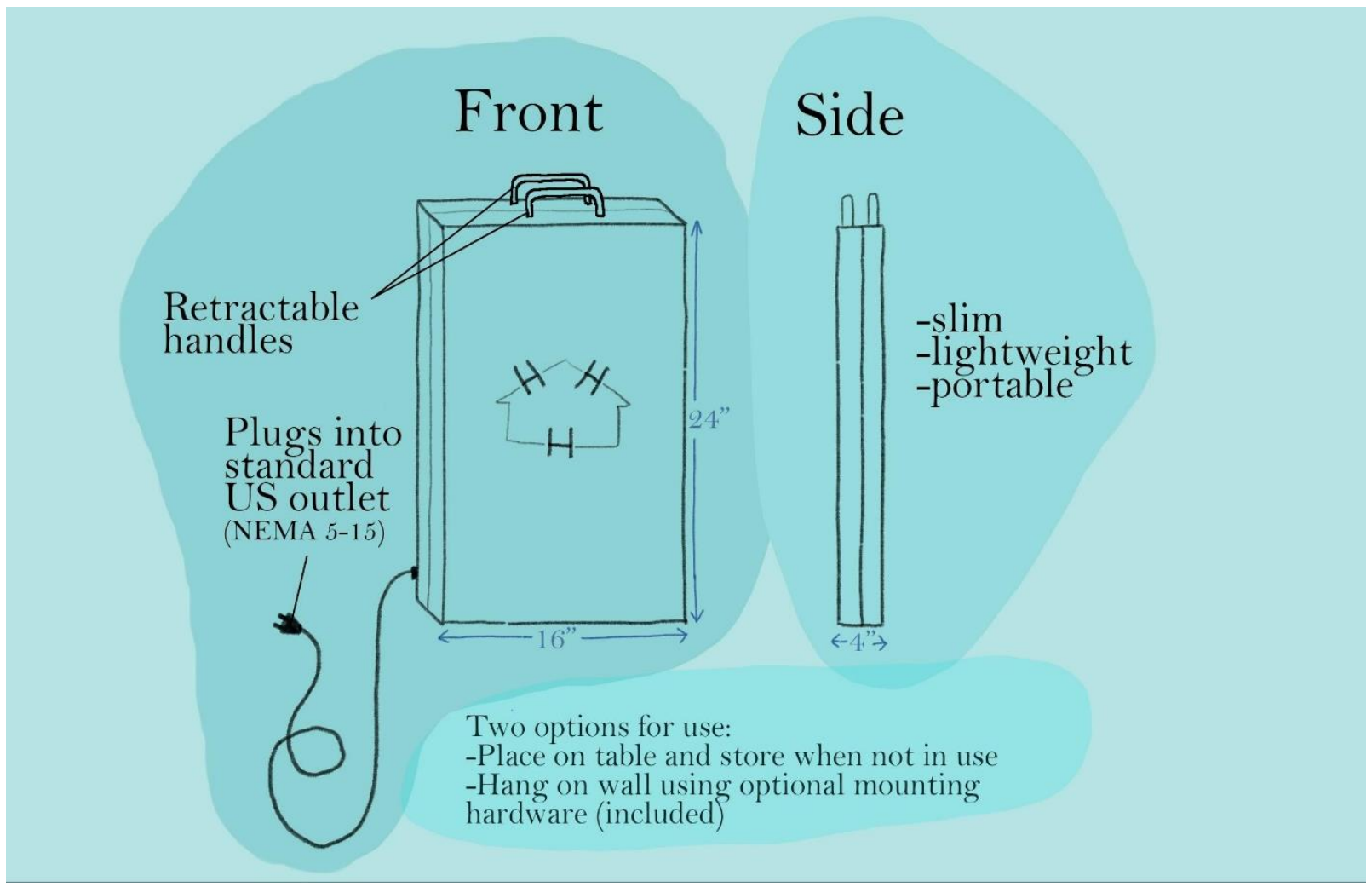

Figure \#1 Exterior View of Home Health Hub

Note: A view of the exterior of Home Health Hub from the front and side, displaying dimensions and key features.

When Home Health Hub is in use, it unfolds to reveal its function as a folding desk (Figure 2). The upright side of the system includes shelves for the storage of medications and supplies. Devices are stored in a modular format. There is a channel at the top of the desk to allow users to place tablets or phones upright for telehealth visits. Home Health Hub offers five RPM devices, in addition to a cellular-enabled tablet for those patients who do not have a device at home. The five devices include a scale, thermometer, blood pressure monitor, blood glucose monitor, and smartwatch. The watch includes several features such as fitness tracking, fall detection, pulse oximetry, heart rate, ECG, as well as respiratory rate. 


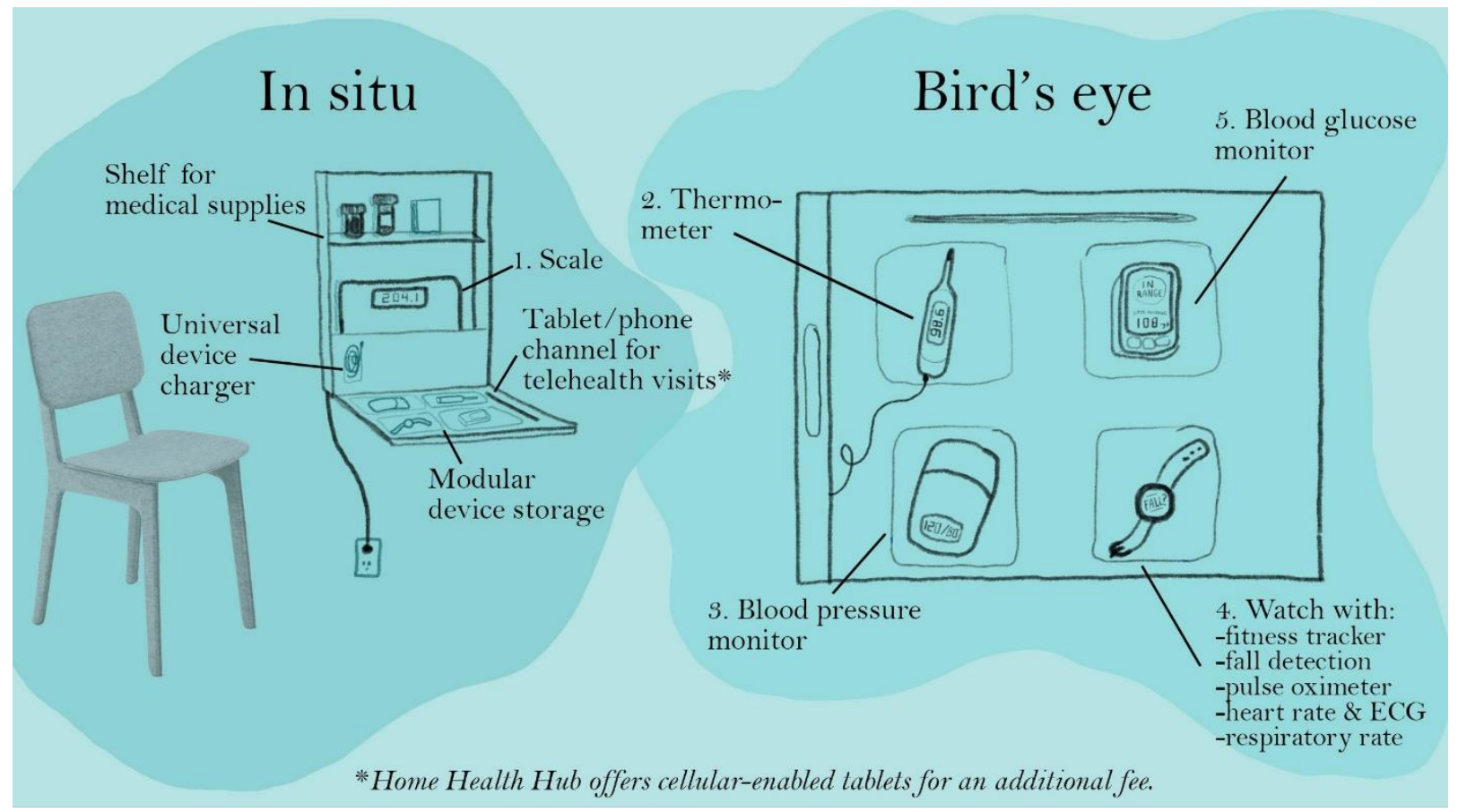

Figure \#2 Home Health Hub in situ and bird's eye view

Note: On the left, a view of Home Health Hub in situ. The system is mounted to the wall and reveals the shelves allowing for the storage of medical supplies. On the right, a bird's eye view of Home Health Hub including RPM devices.

The process of creating the low-fidelity prototype for Home Health Hub allowed the authors to merge and cement design ideas. It further helped to generate additional plans for the design of the system and the component devices.

\subsection{Features}

All Home Health Hub devices are fully cellular, rechargeable, and ready to use out of the box. They don't require internet access or batteries. In the research stage of our process, digital literacy was identified as a key barrier to successful implementation of RPM devices for older adult telehealth users. Cimperman and authors write that, "the level at which HTS (Home Telehealth Services) are perceived as easy to use and manage is the leading acceptance predictor in older users' HTS acceptance" [12]. This barrier presents an opportunity to design a product that is accessible to all users regardless of digital literacy. The simple patient portal provides personalized feedback on easy-to-read health metrics. It also allows its users to access community networking, and nutrition and fitness guides. Technical and clinical support are standing by to guide our users through enrollment and can be reached over the phone, via text, or through our app 24/7. Instant guidance is provided on out-of-range readings from expert health coaches. For interested users, the Home Health Hub app patient portal is convenient and informative. However, use of the patient portal is completely optional and not required to get full use of the devices. Varying levels of digital literacy and digital interest mean that some users may never care for the app regardless of how much customer support they receive. Regardless of patient portal usage, the patient's health metrics are sent seamlessly to their provider. 
Home Health Hub was designed to remove some of the most critical obstacles for providers. The provider dashboard consists of simple graphs and tables of health metrics providing a comprehensive understanding of each patient in a glance and seamlessly syncing with their EHR. Home Health Hub strives to pay attention to compliance, so providers can focus on their patients. It is fully HIPAA compliant for app and video care coordination.

\subsection{Payment Model}

The authors developed a proposed payment model that utilizes partnerships with insurance providers to pay a monthly capitated rate for each user. Additionally, CMS has expanded reimbursements for RPM and chronic care management for the 2020 year increasing revenue potential for providers, ease of insurance coverage, and ability to offer the platform free to patients.

This payment model is viable based on success in other industries. Car insurance companies are lowering premiums for customers that drive safely [13]. A similar model could be applied to incentivize insurers to cover the cost of Home Health Hub for their patients, knowing it will translate to savings [12]. Additionally, adherence requirements ensure use and positive outcomes. If a patient is found to not be using their device according to treatment recommendations, they will be contacted by Home Health Hub health coaches to troubleshoot and receive support with using their devices as directed.

\section{Limitations}

The authors designed multiple iterations of Home Health Hub, beginning with low fidelity models and increasing the level of fidelity with each prototype; however, some limitations should be noted stemming from the context of this being work completed in a graduate Digital Health course. These limitations include the need to identify barriers to market entry, increase interview sample size and selection, and conduct further market research.

The design thinking process established a creative framework for the authors to design a product which would meet the increasing need for older adults to connect with health care providers, monitor their health remotely, and assist with the organization of health artifacts. The proposed product should be further refined with a focus on producibility and market entry in order to increase the odds that it would be successful.

The older adults and caregivers selected to be interviewed for this project were identified via a convenience sample, and a total of four interviews were conducted. The product may be better refined if informed by a larger interview pool or survey effort.

A few RPM platforms were studied in the design thinking process and their best features were considered and improved upon in the creation of Home Health Hub. A more robust comparative research analysis of existing RPM platforms and home health tools could improve the constitution of the product. 


\section{Next steps}

Successful implementation and introduction of Home Health Hub would be demonstrated by an overall decrease in medical spending, emergency room visits, hospital admissions, and hospital readmissions. Likewise, an increase in provider revenue and medication compliance for Home Health Hub users would be indicators of success. Finally, the opportunity to partner with major healthcare providers would allow a wider audience beyond the initial target population to use and benefit from Home Health Hub for preventative care regardless of age or health status.

\section{Conclusion}

Home Health Hub, designed through the design thinking process, is proposed as a solution to telehealth and RPM needs. It is a place in the home designed specifically for users to be able to conveniently access their health care information, RPM devices, and providers. The authors designed a product aiming to address patient vital collection for telehealth appointments in the target population of older adults and beyond.

The design thinking process carried the authors further in the development of Home Health Hub than research would have alone. It was tempting to begin designing a product on day one- the very moment we were given a problem to solve. In retrospect, it is easy to see how you don't know what you don't know. The authors began the process with interviews that opened our eyes to our own unrealized judgments and biases. Initially, we might not have included a patient portal in our design. But after interviewing older friends and loved ones we found that while some are less than interested in digital literacy, others are very tech-savvy and passionate about patient and provider engagement, and ownership of health metrics and records. We took the interviews and applied them to the design of our personas.

The personas forced us to see the world from multiple perspectives and begin to envision a product that served them all equally and efficiently. Once we had the personas in mind, we were able to clearly identify what kinds of barriers would affect each one and come up with solutions and opportunities to get beyond them. To develop the scenarios that led each persona to take an interest in Home Health Hub, we imagined what a day in the life would be like for Jim, Billy, Carmen, and Caveh.

When we began to ideate, we embodied a "yes, and" communication style and embraced each other's ideas no matter how wacky they seemed at the onset. The "murphy bed of health," which began as a silly injection, turned into one of the core features of our product. By the time we began prototyping Home Health Hub, we had done enough research and ideation that we could see clearly what our target population needed and what we wanted to design. If there was a feature that seemed advantageous to include in Home Health Hub, we tried to validate it.

The authors were able to design the unicorn of all RPM platforms that addresses the limitations of existing platforms yet is feasible to implement. Design thinking empowered us to work together to understand our problem and think critically and imaginatively about our solution in a way that wouldn't otherwise have been possible. Home Health Hub is the proud result of this process. Design thinking provides a process that has the potential to solve other key public health challenges 
by supporting a process that systematically focuses a group on creative solutions that address complex needs and constraints of stakeholder populations.

\section{References}

1. Covid-19 pandemic drives telehealth boom, but older adults can't connect. (2021, March 25). Retrieved April 02, 2021, from https://www.ucsf.edu/news/2020/08/418201/covid-19pandemic-drives-telehealth-boom-older-adults-cant-connect

2. What is telehealth? How is telehealth different from telemedicine? (2019, October 17). Retrieved December 18, 2020, from https://www.healthit.gov/faq/what-telehealth-howtelehealth-different-telemedicine

3. Fact Sheet. Telehealth. (n.d.). Retrieved December 18, 2020, from Aha.org website: https://www.aha.org/factsheet/telehealth

4. Understanding telehealth. (n.d.). Retrieved December 18, 2020, from https://telehealth.hhs.gov/patients/understanding-telehealth/

5. VivaLNK. (2019, June 25). Survey Shows Reducing Doctor Visits will Drive Remote Patient Monitoring Adoption. Retrieved December 18, 2020, from https://www.prnewswire.com/news-releases/survey-shows-reducing-doctor-visits-willdrive-remote-patient-monitoring-adoption-300874238.html

6. Hennick C. (2020, April 27). How remote patient monitoring programs are beneficial. Retrieved December 18, 2020, from Publisher website: https://healthtechmagazine.net/article/2020/04/how-remote-patient-monitoring-programsare-beneficial

7. Malkary G. (2019, October). Trends in Remote Patient Monitoring. Retrieved December 18, 2020, from https://www.spyglassconsulting.com/Abstracts/Spyglass_RPM2019_abstract.pdf

8.0B]Livongo: An easy way to fit health into your life. hello.livongo.com. (n.d.). Retrieved November 20, 2020, from https://hello.livongo.com/GEN/TLD?experiment_id=vwo168_gen

9. Remote Patient Monitoring Devices. 100Plus. (n.d.). Retrieved May 27, 2021 from https://www.100plus.com/

10. Quality Initiatives - General Information. (2019, November). Retrieved December 18, 2020, from https://www.cms.gov/Medicare/Quality-Initiatives-Patient-AssessmentInstruments/QualityInitiativesGenInfo

11. Dupree, O., Kolnik, H., Miller, J. (2019, November 23). Personal interview 
12. Cimperman M, Brenčič MM, Trkman P. 2016. Analyzing older users' home telehealth services acceptance behavior - applying an Extended UTAUT model. Int J Med Inform. 90, 22-31. doi:https://doi.org/10.1016/j.ijmedinf.2016.03.002. PubMed

13. Metz J. (2020, December 10). Usage-Based Insurance Rewards Good Drivers. Retrieved December 18, 2020, from https://www.forbes.com/advisor/car-insurance/usage-basedinsurance/

\section{Acknowledgments}

The authors express gratitude to Alison Bryant, $\mathrm{PhD}$, Senior Vice President, AARP Research \& Enterprise Lead, Tech \& Digital Equity, for providing the original challenge that led to this work. We also appreciate her guidance throughout the design thinking process and feedback on Home Health Hub throughout the process. The authors also thank Avi Patel, MD Candidate. Tufts School of Medicine '23, for his thoughtful review of the document.

\section{$\underline{\text { Appendix A }}$}

SWOT Analyses

SWOT Analysis: Home Kits

\begin{tabular}{|c|c|}
\hline $\begin{array}{l}\text { STRENGTHS } \\
\text { - Convenient } \\
\text { - No transportation required } \\
\text { - Some have personalized } \\
\text { messaging/coaching feature } \\
\text { - Some are cellular }\end{array}$ & $\begin{array}{l}\text { WEAKNESSES } \\
\text { - Potential for error/not medical grade } \\
\text { - Some require Wi-Fi } \\
\text { - Require some degree of digital } \\
\text { literacy }\end{array}$ \\
\hline $\begin{array}{l}\text { OPPORTUNITIES } \\
\text { - Emerging/unmet need due to COVID- } \\
19 \\
\text { - Wide range of design possibilities } \\
\text { - Can be configured to meet various } \\
\text { combinations of needs }\end{array}$ & $\begin{array}{l}\text { THREATS } \\
\text { - Sanitation/cleanliness } \\
\text { - Misuse due to lack of digital literacy }\end{array}$ \\
\hline
\end{tabular}

\section{SWOT Analysis: Kiosks}

\section{STRENGTHS}

- Cost-effective

- Doesn't require individual purchase or storage of products

\section{WEAKNESSES}

- Requires transportation/not ideal for rural health care 


\begin{tabular}{|c|c|}
\hline & $\begin{array}{l}\text { - Not ideal for patients with mobility } \\
\text { concerns } \\
\text { - Not available } 24 / 7 \\
\text { - Not available for all vitals collection } \\
\text { - May become expensive if used often }\end{array}$ \\
\hline $\begin{array}{l}\text { OPPORTUNITIES } \\
\text { - Emerging/unmet need due to COVID- } \\
19 \\
\text { - Wide range of design possibilities } \\
\text { - Can be configured to meet various } \\
\text { combinations of needs }\end{array}$ & $\begin{array}{l}\text { THREATS } \\
\text { - Pay out-of-pocket/not reimbursed by } \\
\text { insurance } \\
\text { - Misuse due to lack of digital literacy } \\
\text { - Interpretation of results }\end{array}$ \\
\hline
\end{tabular}

\section{$\underline{\text { Appendix B }}$}

\section{Complete Interview Question List}

1. Do you have internet access at home?

2. Do you own a smartphone?

3. Are you comfortable using digital technology such as cellphones, computers, tablets?

4. Do you have any chronic conditions that require regular monitoring?

a. How many?

5. Have you ever taken your vitals at home?

a. If yes:

i. Are there health indicators that you monitor regularly?

ii. How hard is it to take your vitals at home, on a scale of 1 (easy) to 10 (hard)

1. If score 1-4, why is it easy/relatively easy?

2. If score 5+, why is it relatively hard/hard?

6 . How did you share your results with your doctor?

7. How much did your self-taken vitals influence your conversation with your doctor?

a. If no:

i. Why not? (Lack of resources, etc.)

8. Do you think it's important to check your vitals regularly? Why or why not?

\section{Appendix C}

Complete List of Personas and Scenarios

\begin{tabular}{|l|l|l|}
\hline Name & Jim & \\
\cline { 1 - 2 } Age & 78 & \\
\hline
\end{tabular}




\begin{tabular}{|c|c|c|}
\hline Sex/Gender & Cisgender Male & \\
\hline $\begin{array}{l}\text { Race/Ethnicit } \\
\text { y }\end{array}$ & White (Non-Hispanic/Latinx) & \\
\hline Marital Status & Widower & \\
\hline $\begin{array}{l}\text { Education } \\
\text { Level }\end{array}$ & High School Graduate & \\
\hline Location & Rural Minnesota & \\
\hline $\begin{array}{l}\text { Brief } \\
\text { Description }\end{array}$ & \multicolumn{2}{|c|}{$\begin{array}{l}\text { Jim is a veteran living in a rural setting, with mobility issues and chronic } \\
\text { conditions (cardiovascular disease and PTSD). Jim does not have wifi or a } \\
\text { smartphone. He has an independent attitude and is somewhat introverted. His } \\
\text { children and small circle of friends are his social supports. }\end{array}$} \\
\hline Scenario & \multicolumn{2}{|c|}{$\begin{array}{l}\text { Jim has learned through a mailing advertisement that his psychiatrist and primary } \\
\text { care provider, both associated with the same rural hospital, have begun offering } \\
\text { virtual visits. Jim would like to learn how to access care remotely due to his rural } \\
\text { setting and declining mobility, but he does not feel confident that he can learn to } \\
\text { use RPM technology on his own. Jim's children, who visit him regularly, agree it } \\
\text { would be a good option for him and are ready to support him with setup. }\end{array}$} \\
\hline Quote & \multicolumn{2}{|c|}{$\begin{array}{l}\text { "It would be great if I could cut down on the amount I need to travel in order to } \\
\text { see my doctors." }\end{array}$} \\
\hline
\end{tabular}

\begin{tabular}{|l|l|l|}
\hline Name & Billy & \\
\hline Age & 63 & \\
\hline Sex/Gender & Cisgender Male & \\
Race/Ethnicit & Black/African American & \\
\hline $\begin{array}{l}\text { Marital Status } \\
\text { Education }\end{array}$ & Married & \\
\hline Level & & \\
\hline
\end{tabular}




\begin{tabular}{|l|l|}
\hline Location & Suburban Massachusetts \\
\hline $\begin{array}{l}\text { Brief } \\
\text { Description }\end{array}$ & $\begin{array}{l}\text { Billy lives with high blood pressure. He has internet access at home and a } \\
\text { smartphone but has low digital literacy skills. Billy was recently diagnosed with } \\
\text { type 2 diabetes. }\end{array}$ \\
\hline Scenario & $\begin{array}{l}\text { Billy has been managing his high blood pressure with in-person visits to the } \\
\text { doctors yearly. In December 2019, Billy went into the doctor's office for a } \\
\text { routine check-up and was diagnosed with type 2 diabetes. This new diabetes } \\
\text { diagnosis will require him to visit his doctor every 3 months. In early March, } \\
\text { Billy visited his doctor to have his vitals checked and A1C tested. Shortly after } \\
\text { this visit, COVID-19 hit and everyone was advised to stay in their homes. In June } \\
\text { he was due for more testing but was very uneasy going into the doctor's office } \\
\text { due to the current pandemic and his new diagnosis. Billy would love to learn how } \\
\text { to safely manage his care from home. }\end{array}$ \\
\hline Quote & $\begin{array}{l}\text { 'I want to do what's best for my health, but I am worried about going into the } \\
\text { doctor's office during a pandemic." }\end{array}$ \\
\hline
\end{tabular}

\begin{tabular}{|c|c|c|}
\hline Name & Carmen & 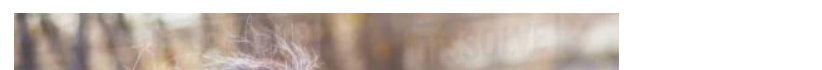 \\
\hline Age & 56 & 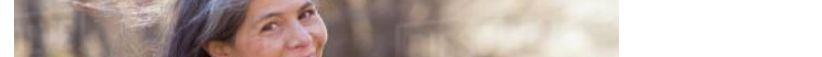 \\
\hline Sex/Gender & Cisgender Female & (1) \\
\hline $\begin{array}{l}\text { Race/Ethnicit } \\
\text { y }\end{array}$ & Latina - Columbian & Nat \\
\hline Marital Status & Married & \\
\hline $\begin{array}{l}\text { Education } \\
\text { Level }\end{array}$ & Bachelor's Degree & \\
\hline Location & Long Island, NY & \\
\hline $\begin{array}{l}\text { Brief } \\
\text { Description }\end{array}$ & \multicolumn{2}{|c|}{$\begin{array}{l}\text { Carmen recently retired after more than } 30 \text { years in hospital administration and is } \\
\text { loving retired life! She can't sit still. Her weekly activities include salsa dance } \\
\text { classes, singing in her church choir, a walking group with other women in her } \\
\text { neighborhood, and swimming lessons. }\end{array}$} \\
\hline
\end{tabular}




\begin{tabular}{|l|l|}
\hline Scenario & $\begin{array}{l}\text { Carmen had a mild heart attack in her late 40s and has taken charge of her health } \\
\text { ever since. She eats well, exercises every day and is the healthiest she's ever } \\
\text { been. She still has bouts of high blood pressure and works with her doctor to } \\
\text { keep it at bay. She has an annual visit coming up and laments having to go to the } \\
\text { doctor. She'd rather be having fun! }\end{array}$ \\
\hline Quote & $\begin{array}{l}\text { "I would love to have my annual visit from home. It takes too long to get to and } \\
\text { from my doctor's office and if I have to go in for my next appointment I'll be } \\
\text { late for salsa class!" }\end{array}$ \\
\hline
\end{tabular}

\begin{tabular}{|c|c|c|}
\hline Name & Caveh & a) \\
\hline Age & 33 & $1 / 2$ \\
\hline Sex/Gender & Genderqueer/Non-binary & 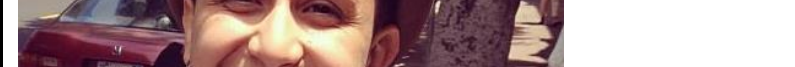 \\
\hline $\begin{array}{l}\text { Race/Ethnicit } \\
\text { y }\end{array}$ & Asian - Persian & $=10$ \\
\hline Marital Status & Single & \\
\hline $\begin{array}{l}\text { Education } \\
\text { Level }\end{array}$ & Doctorate & \\
\hline Location & San Francisco, CA & \\
\hline $\begin{array}{l}\text { Brief } \\
\text { Description }\end{array}$ & \multicolumn{2}{|c|}{$\begin{array}{l}\text { Caveh is a Physical Therapist and part-time caregiver for their father, Rashad. } \\
\text { They are tech-savvy and enthusiastic about helping Rashad receive the best care } \\
\text { possible. }\end{array}$} \\
\hline Scenario & \multicolumn{2}{|c|}{$\begin{array}{l}\text { Caveh is very engaged in Rashad's health and prefers to accompany him to his } \\
\text { doctor's visits. Unfortunately, this is not always possible due to their busy work } \\
\text { and commute schedule. Rashad has Type } 2 \text { diabetes, so Caveh helps Rashad } \\
\text { manage his care from home with the help of an insulin pump, regular exercise, } \\
\text { healthy eating, stress management and regular observation of his blood pressure } \\
\text { and cholesterol levels. Caveh learns that his father's provider is now offering } \\
\text { virtual visits but is concerned that vital health information may be missed } \\
\text { without access to the same tools used in the doctor's office. }\end{array}$} \\
\hline
\end{tabular}


\begin{tabular}{l|l} 
Quote & "If we could monitor my dad's vitals and meet with his providers from home it
\end{tabular} would be easier for me to make sure he's getting all the information and support he needs." 